\title{
Distúrbios músculo-esqueléticos e as atividades de trabalho em uma empresa de reciclagem: um enfoque em aspectos físicos
}

\section{Musculoskeletal disorders and work activities in a recycle company: focusing on the physical aspects}

\author{
Maria do Carmo Baracho de Alencar ${ }^{1}$
}

ALENCAR, M. do C. B. de. Distúrbios músculo-esqueléticos e as atividades de trabalho em uma empresa de reciclagem: um enfoque em aspectos físicos. Rev. Ter. Ocup. Univ. São Paulo, v. 20, n. 2, p. 126-134, maio/ago. 2009.

RESUMO: O objetivo deste estudo foi o de investigar fatores de risco de distúrbios músculoesqueléticos em atividades de trabalho de operadores de produção de uma empresa de materiais recicláveis. Os métodos consistiram de seleção das tarefas percebidas como de maior esforço físico entre os trabalhadores, aplicação de um questionário elaborado contendo: dados demográficos, questões relacionadas ao trabalho, e questões do Questionário Nórdico de Sintomas Músculoesqueléticos (QNSO) validado no Brasil (Pinheiro et al., 2002); levantamentos das tarefas e observações sistemáticas das atividades, com base na Ergonomia (Guérin et al., 1997). Participaram do estudo seis trabalhadores operadores de produção, do gênero masculino, com idade entre 18 e 33 anos. As tarefas selecionadas para o estudo foram: descarregamento dos caminhões (de 3 tipos) e a colocação dos fardos nos pallets. Para complementar as observações foram utilizados os instrumentos: filmadora e câmera digital (registro de posturas), fita métrica (medições dos fardos), e cronômetro (tempo/velocidade e tempo/pausas). Nos resultados, os trabalhadores apresentaram queixas de dores músculo-esqueléticas em regiões de ombros, cotovelos e coluna (região lombar). Presença de aspectos da organização do trabalho: ritmo intenso de trabalho, pressão temporal, tempo insuficiente de pausas, pobre relacionamento com supervisor; que favorecem o surgimento de dores músculo-esqueléticas, e também encontrado "insatisfação" em geral no trabalho. Conclui-se que é importante dar atenção aos aspectos organizacionais e psicossociais para a prevenção de distúrbios músculo-esqueléticos no trabalho.

DESCRITORES: Transtornos traumáticos cumulativos; Ambiente de trabalho/prevenção \& controle; Trabalho/psicologia; Engenharia humana; Terapia ocupacional.

\footnotetext{
1. Profa. do curso de Terapia Ocupacional da Universidade Federal de São Paulo.

Endereço para correspondência: Rua Prof. Torres Homem, 570- apto.63. Santos- SP, CEP: 11025-021. E.mail: belinha.alencar1@gmail. com
} 


\section{INTRODUÇÃO}

$\mathrm{O}$ s distúrbios osteomusculares ou músculoesqueléticos relacionados ao trabalho (DORT), continuam crescendo entre a população de trabalhadores, e o problema continua sendo uma preocupação dentro do tema sobre promoção à saúde no trabalho. As DORTs incluem uma variedade de condições inflamatórias e degenerativas afetando os músculos, tendões, ligamentos, articulações, nervos periféricos, etc; incluindo: inflamações em tendões (tendinites), tenossinuvites, bursites, compressões nervosas (como síndrome do túnel do carpo, dor ciática), bem como outras condições como mialgias, lombalgias, etc. (PUNNET; WEGMAN, 2004). Segundo o Ministério da Saúde (2006) são caracterizados por sintomas como dor, parestesia, sensação de peso e fadiga; e de aparecimento insidioso.

Estudos trazem como fatores de risco para o surgimento de DORTs: utilização de força muscular, repetição de movimentos, posturas estáticas prolongadas, sendo esses fatores associados às variáveis intensidade e exposição temporal, entre outros (KUMAR, 2001; MARRAS, 2000). Forde et al. (2002) citam como fatores de risco: estresse mecânico localizado, poucas pausas, posturas inadequadas, e aspectos relacionados à organização do trabalho, como alta demanda e pouco controle no trabalho. A Organização Mundial de Saúde (OMS) caracterizou as doenças músculoesqueléticas relacionadas ao trabalho como multifatoriais, envolvendo fatores físicos, organizacionais, psicossociais, aspectos individuais e socioculturais (RIO, 1998).

Sob enfoques preventivos, atualmente uma atenção especial tem sido dada aos aspectos organizacionais e psicossociais do trabalho, decorrente das mudanças ocorridas no mundo do trabalho pelo processo de globalização econômica mundial. Entre os aspectos relacionados à organização do trabalho e o surgimento dos DORTs estão o caráter repetitivo das tarefas, ritmo intenso de trabalho, ausência de treinamentos, horas extras de trabalho, entre outros (COLOMBINI; OCCHIPINTI, 2006). Exigências de comprometimento com os objetivos e metas de produtividade, e aspectos relacionados ao ambiente de trabalho (MELZER, 2008). Há associações entre os DORTs e aspectos psicossociais, como: pressão no trabalho, pouca influência no trabalho, pobre relacionamento com supervisores e colegas no trabalho, falta de controle no trabalho, trabalho monótono, entre outros; que são encontrados em vários estudos (DAVIES; HEANEY, 2000; ARIENS et al., 2001; FENG et al., 2007; SMITH et al., 2006).

Segundo Dejours (1992) por Organização do Trabalho entende-se a divisão do trabalho, o conteúdo da tarefa, sistema hierárquico, modalidades de comando, relações de poder, etc. A Organização do Trabalho influencia no planejamento, execução e avaliação das etapas dos processos de trabalho, prescrevendo regras, normas e alguns parâmetros norteadores. E representa os aspectos psicossociais no trabalho, o conjunto de percepções e experiências do trabalhador, que segundo Camelo \& Angerami (2008) consistem em interações entre o trabalho e o ambiente de trabalho, organização do trabalho; e por outro lado as características pessoais do trabalhador.

Um dos marcos históricos em relação à Organização do Trabalho ocorreu na época da Segunda Revolução Industrial. A Segunda Revolução Industrial, no final do século XIX e início do século XX, nos Estados Unidos, foi caracterizada pela Administração Científica do trabalho e pela produção em série. A Teoria da Administração Científica iniciada por Frederick W. Taylor (Taylorismo), defendia que o trabalho deveria ser cientificamente observado de modo que para cada tarefa, fosse estabelecido um método de executá-la, com tempo determinado, e ferramentas corretas; sendo que os trabalhadores deveriam ser controlados, avaliando sua produtividade e pagando incentivos salariais aos que eram mais produtivos (IIDA, 2002). Segundo Merlo e Lápis (2007), o Taylorismo se associa à criação de uma estrutura organizacional rígida, hierarquizada, com normas burocráticas e vigilância de supervisores; transformando o trabalho em atividade parcelada, repetida e sem sentido, retirando do trabalhador a capacidade criativa. Lancman e Uchida (2003) citam que quando Taylor propôs a Organização Científica do Trabalho, aparentemente propôs eliminar a subjetividade do trabalho; impossibilitando o trabalhador de expressar pensamentos e desejos na condução das atividades. Entende-se por subjetividade a síntese individual e singular que cada um de nós constitui ao longo de seu desenvolvimento, vivenciando diversas experiências da vida social e cultural (RUSSO; TOLEDO, 2006).

A partir da década de 1910, a organização do trabalho expandiu-se e seus princípios foram difundidos com os métodos e tecnologia utilizada por Henry Ford (Fordismo). O Fordismo segundo Merlo e Lápis (2007) manteve a divisão do trabalho e a fragmentação das tarefas. Há algum tempo vem se debatendo os efeitos negativos dessa organização do trabalho taylorista/ fordista. Segundo Matos e Pires (2006) destacam-se a fragmentação do trabalho, associando o controle gerencial do processo à hierarquia rígida, que tem levado à desmotivação e alienação de trabalhadores.

Para o Ministério da Saúde (2006) a alta prevalência de LER/DORT em trabalhadores tem sido explicada pelas transformações do trabalho e das empresas, com 
organização caracterizada por exigências quanto às metas $\mathrm{e}$ produtividade, não levando em conta os trabalhadores com seus limites físicos e psicossociais.

$\mathrm{O}$ trabalho implica em tarefa e atividade, sendo para a Ergonomia (corrente francesa) a tarefa é o que é prescrito para ser feito, e a atividade o que é realizado efetivamente pelo trabalhador para executar a tarefa. A atividade de trabalho para Guérin et al. (1997) "é um conjunto dos fenômenos (fisiológicos, psicológicos, psíquicos, etc) que caracterizam o ser humano cumprindo atos". Para Falzon (2007) a atividade inclui o observável e o inobservável: a atividade intelectual e mental; para o autor, se a atividade é estimulante, e ao mesmo tempo realizável, há efeitos positivos, como desenvolvimento de competências, interesses pelo trabalho, sentimento de utilidade, satisfação.

A partir de uma demanda de distúrbios músculoesqueléticos em um grupo de trabalhadores, é que se deu início a este projeto, por solicitação da empresa. O objetivo do estudo foi o de investigar fatores de risco de distúrbios músculo-esqueléticos em atividades de trabalho com maiores relatos de esforços físicos, de operadores de produção de uma empresa de materiais recicláveis.

\section{MATERIAIS E MÉTODOS}

Este estudo é exploratório, e é um estudo de caso. Após uma visita inicial foi elaborado um projeto e apresentado aos dirigentes, e após autorização iniciou-se o estudo. Obtiveram-se inicialmente os dados da empresa: atividade principal, horários de funcionamento, dados sobre os setores de trabalho, fluxograma do trabalho, número de funcionários, tempo na empresa, entre outros. Posteriormente foram levantadas as tarefas de maiores exigências físicas, a partir das falas dos próprios trabalhadores (percepções sobre o esforço físico), sendo estas: descarregamento dos caminhões e colocação dos fardos nos pallets; sendo estas as tarefas selecionadas para o estudo.

Foi elaborado um questionário para aplicação junto aos trabalhadores, contendo dados demográficos, e algumas questões relacionadas ao trabalho. Em relação aos distúrbios músculo-esqueléticos também foi aplicado questões do Questionário Nórdico de Sintomas Osteomusculares (QNSO), validado no Brasil (PINHEIRO et al., 2002), com a ocorrência de sintomas (dor, desconforto, ou formigamento) nas várias regiões anatômicas (pescoço, ombros, coluna, ombros, cotovelos, punhos e mãos, quadril, joelho, tornozelo e pé), intensidade de sintomas nos últimos doze meses, nos últimos sete dias, e o afastamento do trabalho nos últimos doze meses. O índice de severidade dos sintomas variam de 0 à 4 , onde 0 representa ausência de sintomas. Foi incluído no questionário questões se havia história de lesão músculo-esquelética nos últimos doze meses; e sobre a percepção em relação ao esforço físico, com respostas entre: leve, moderado, intenso, sem esforço (com uma única resposta para as tarefas).

Posteriormente foram realizados levantamentos das tarefas e observações sistemáticas das atividades, com base na Ergonomia (GUÉRIN et al., 1997) durante um período de dois meses, e realizada por um tempo médio de uma hora e meia, três vezes por semana. Para complementar as observações, alguns instrumentos foram utilizados: papel e caneta para anotações de falas durante o trabalho e outros registros importantes para o estudo: filmadora e câmera digital marca Kodak (modelo EasyShare C533) para registro de posturas "críticas" no trabalho, fita métrica com precisão de milímetros para avaliar as dimensões dos fardos (latas prensadas) que eram utilizados nas tarefas, e cronômetro marca Casio (modelo HS-3) para medições de tempos (seis medidas obtidas/tempo de sessenta segundos por dia observado, em trabalhadores alternados, e em momentos alternados durante duas semanas; e seis medidas obtidas/ tempo de pausas durante três minutos em momentos também alternados, por dia observado, no mesmo período de duas semanas), e balança do próprio local, que era utilizada para pesar as sacarias (latas em sacos que eram compradas) e que foi utilizada para pesar os fardos. Tanto para a aplicação dos questionários quanto para as observações entre outros, houve consentimento e autorização prévia dos trabalhadores.

Posteriormente os dados foram analisados. Haviam dois trabalhadores afastados, um por acidente de trânsito, e outro por acidente de trabalho na época da pesquisa, não inclusos no estudo.

\section{RESULTADOS E DISCUSSÃO}

A principal atividade da empresa é a reciclagem. Sendo seis os operadores de produção participantes do estudo, todos do gênero masculino, com idade entre 18 e 33 anos, e tempo de serviço entre um mês e cinco meses, entre cinco dos trabalhadores; e um trabalhador com tempo de serviço de um ano e três meses. Quanto ao grau de escolaridade dos trabalhadores: apenas um trabalhador com segundo grau completo, e demais trabalhadores com primeiro grau incompleto ou completo.

O horário de funcionamento da empresa era das 08:00 às 18:00h, de segunda à sexta-feira, com horário para o almoço entre 12:00 e 13:00h. A empresa faz o recebimento de latas de bebidas, avulsas inteiras ou já prensadas, e prensadas e unidas (denominadas de 
"fardo"), e as organiza em pallets de madeira (estruturas para carregamento) para armazenamento e transporte em caminhões, que os levam para as empresas de reciclagem. Das instalações, as mesmas constituem de um galpão grande com uma máquina de prensar as latas, duas salas de trabalho administrativas, cozinha e banheiro; e um número total de 12 funcionários.

As tarefas dos operadores de produção I e II, são: carregar e descarregar latas no caminhão, abrir sacarias, trabalhar na esteira, selecionar latas, montar pallets, limpar equipamentos, amarrar fardos, operar prensas. O local do trabalho é um galpão, onde há uma máquina de prensar as latas, com presença de ruído; sendo necessário a utilização de protetores auriculares.

Os trabalhadores não relataram história de lesão músculo-esquelética nos últimos doze meses. Não houve afastamento do trabalho entre os entrevistados, nos últimos doze meses, e a maioria não tinha este tempo de serviço. Os trabalhadores não trabalhavam em outro local, e não relataram treinamento prévio para o trabalho. As regiões das dores músculo-esqueléticas entre os trabalhadores, estão demonstradas no Gráfico 1.

GRÁFICO 1. Regiões das dores músculo-esqueléticas entre os trabalhadores, nos últimos sete dias

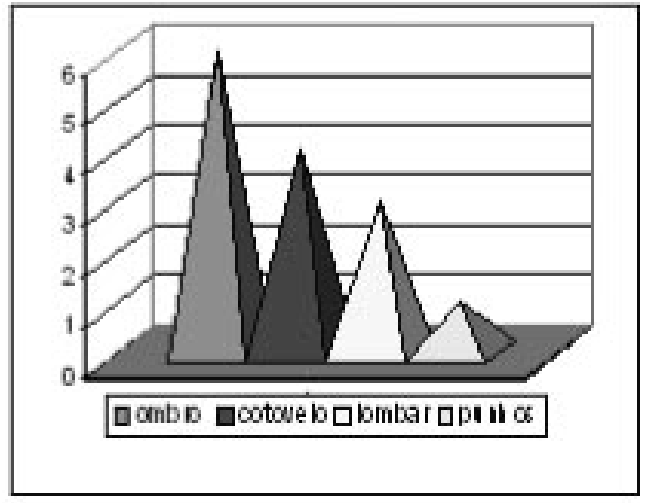

Em relação às dores músculo-esqueléticas presentes nos últimos sete dias, houve seis queixas de dores em região do ombro, quatro queixas em região de cotovelo, três queixas em região lombar, e uma queixa em região de punhos; sendo que alguns trabalhadores apresentaram mais de uma queixa. Quanto ao índice de severidade dos sintomas estes foram de $4 \mathrm{em} 5$ trabalhadores e de $3 \mathrm{em}$ um trabalhador (de 0 à 4 ), indicando o nível de desconforto do sintoma e o risco para lesão.

As tarefas selecionadas para o estudo foram: descarregamento dos caminhões, e colocação dos fardos sobre os pallets.

\section{O descarregamento dos caminhões}

O descarregamento dos caminhões era realizado de três formas (descritas em descarregamento dos tipos A, B e C), conforme demonstrado na Tabela 1.

Observa-se na Tabela 1, um ritmo acelerado nos descarregamentos tipos A, B e C, pelo tempo médio gasto para a realização das tarefas, e aliado a uma percepção de esforço físico intenso especialmente nos tipos A e
$\mathrm{B}$; ainda pouco tempo de pausas, o que pode facilitar o surgimento de fadiga muscular. O descarregamento do tipo A ocorre com maior frequência diária. Não havia um controle quanto aos horários de chegada dos caminhões, o que muitas vezes gerava sobrecarga de trabalho, especialmente quando chegavam em horários próximos uns dos outros. As tarefas eram realizadas conforme as ordens de um supervisor.

Quanto às características gerais dos fardos, o peso a partir de seis medidas obtidas (balança do local), em dias e horários alternados, eram entre 14,700 e 24,000kg, com média de $17,180 \mathrm{~kg}$. Sendo que o peso dos mesmos em alguns momentos estava acima de $20,000 \mathrm{~kg}$ e associados aos movimentos repetitivos, fator de risco para os distúrbios músculo-esqueléticos. Quanto ao tamanho e formato dos fardos a partir de seis medidas (medidas: largura e comprimento, com fita métrica) em dias e horários alternados: eram entre 19,0 x $44,0 \mathrm{~cm} / 25,0 \times 47,0$ $\mathrm{cm} ; 25,0 \times 50,0 \mathrm{~cm} / 30,0 \times 50,0 \mathrm{~cm}$, e os formatos eram retangulares. As dimensões não padronizadas exigiam uma maior atenção nos manuseios manuais. As sacarias variavam de peso entre 2,800 e $4,000 \mathrm{~kg}$. 
ALENCAR, M do C. B. de. Distúrbios músculo. Rev. Ter. Ocup. Univ. São Paulo, v. 20, n. 2, p. 126-134, maio/ago. 2009.

TABELA 1. Descarregamento dos caminhões e características gerais

\begin{tabular}{|c|c|c|c|}
\hline \multicolumn{4}{|c|}{ DESCARREGAMENTO DOS CAMINHÕES } \\
\hline Aspectos analisados & Descarregamento: tipo A & Descarregamento: tipo B & Descarregamento: tipo C \\
\hline $\begin{array}{l}\mathrm{N}^{\mathrm{o}} \text { de caminhões } \\
\text { descarregados/dia }\end{array}$ & $\begin{array}{l}\text { 3-4 caminhões cheios por } \\
\text { dia (de fardos). }\end{array}$ & $\begin{array}{l}\text { 1-2 caminhões cheios por } \\
\text { dia (de fardos). }\end{array}$ & $\begin{array}{l}\text { 4-5 caminhões cheios por semana } \\
\text { (sacarias com latas). }\end{array}$ \\
\hline $\mathrm{N}^{\mathrm{o}}$ de trabalhadores/tarefas & De 3 à 4 trabalhadores & 2 trabalhadores & 1 trabalhador \\
\hline $\begin{array}{l}\text { Tempo médio gasto para a } \\
\text { realização das tarefas }\end{array}$ & $\begin{array}{l}\text { Média de } 15,7 \text { fardos por } \\
\text { minuto }(\mathrm{DP}=2,3) \text {, por } \\
\text { trabalhador. }\end{array}$ & $\begin{array}{l}\text { Média de } 13,3 \text { fardos } \\
\text { por minuto }(\mathrm{DP}=1,3) \text { por } \\
\text { trabalhador, }\end{array}$ & $\begin{array}{l}\text { Média de } 9,7 \text { sacarias foram abertas e } \\
\text { jogadas ao chão por minuto }(\mathrm{DP}=1,5) \text {, } \\
\text { por trabalhador. }\end{array}$ \\
\hline Modo de realização (físico) & $\begin{array}{l}\text { Os fardos eram atirados } \\
\text { (jogados) para fora do ca- } \\
\text { minhão, no chão do galpão, } \\
\text { manualmente. }\end{array}$ & $\begin{array}{l}\text { Os fardos eram colocados } \\
\text { nos pallets, manualmente. }\end{array}$ & $\begin{array}{l}\text { Sacarias eram abertas e as latas eram } \\
\text { despejadas para fora do caminhão, } \\
\text { manualmente. }\end{array}$ \\
\hline $\begin{array}{l}\text { Tempo médio total de pausas por } \\
\text { trabalhador em três minutos. }\end{array}$ & $\begin{array}{l}\text { Média de } 7,1 \mathrm{seg} \\
(\mathrm{DP}=0,80)\end{array}$ & Média de $6,8 \operatorname{seg}(\mathrm{DP}=2,2)$ & Média de 4,5 seg $(\mathrm{DP}=2,32)$ \\
\hline $\begin{array}{l}\text { Percepção do esforço físico } \\
\text { pelos trabalhadores }\end{array}$ & Intenso $(\mathrm{n}=6)$ & Intenso $(n=6)$ & Moderado $(n=5)$, leve $(n=1)$ \\
\hline $\begin{array}{l}\text { Regiões corporais onde foram } \\
\text { observados movimentos } \\
\text { repetitivos }\end{array}$ & $\begin{array}{l}\text { Tronco; ombros; antebraço; } \\
\text { punho; mãos. }\end{array}$ & $\begin{array}{l}\text { Tronco; ombros; antebraço, } \\
\text { punho; mãos. }\end{array}$ & $\begin{array}{l}\text { Tronco; ombros; antebraço, punho; } \\
\text { mãos. }\end{array}$ \\
\hline
\end{tabular}

Na Figura 1, observa-se uma das formas de descarregamento dos caminhões.

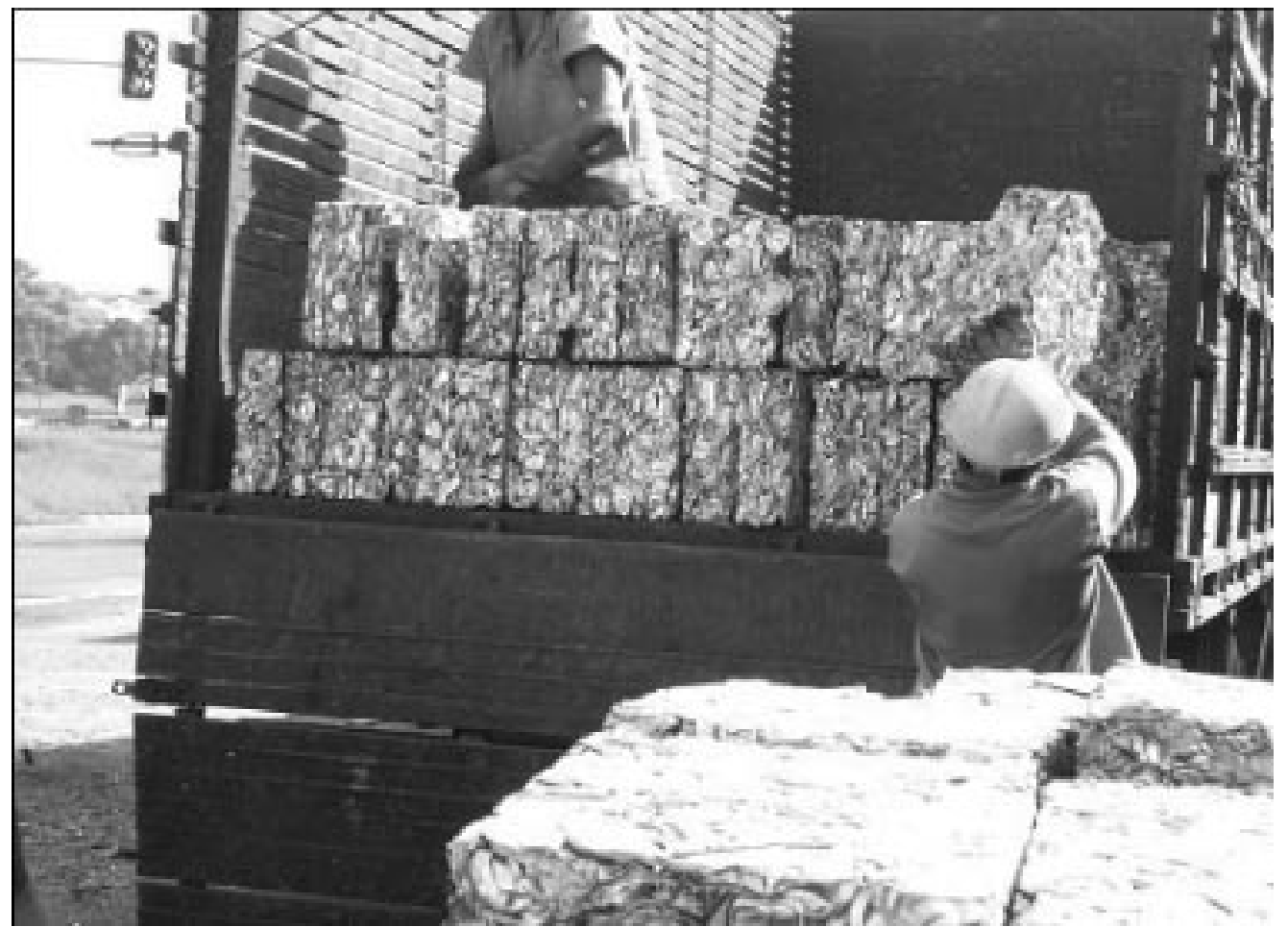

FIGURA 1. Descarregamento dos caminhões (Tipo B) 
Em atividade dinâmica, sob aspectos físicos, alguns movimentos articulares em determinados ângulos são tidos como risco para lesões músculo-esqueléticas, por exercerem sobrecargas tendíneas, musculares e ligamentares. Em todos os tipos de descarregamento, observaram-se movimentos repetitivos dos ombros acima do ângulo de $90^{\circ}$ (flexão e abdução), sendo a região dos ombros deste estudo a região de maior queixa entre os trabalhadores. Em relação aos movimentos do ombro, Punnet et al. (2000) concluíram em seu estudo que movimentos de abdução e flexão severas $\left(>90^{\circ}\right)$ especialmente se ocorrer $10 \%$ ou mais do tempo de trabalho por dia, é um fator de risco para dores em ombros crônicas ou recorrentes. Outra região acometida de dores músculo-esqueléticas entre os trabalhadores foi a de cotovelos, próxima aos epicôndilos lateral e/ ou medial. Em relação aos movimentos de antebraço e riscos de epicondilites, Grieco et al. (1998) citam que movimentos repetitivos e com força de flexão e extensão do punho, pronação e supinação de antebraço, podem causar sobrecargas para as áreas tendíneas inseridas nos epicôndilos lateral e medial. No descarregamento do tipo A, foram observados movimentos de pronação e supinação do antebraço, e flexão e extensão do punho ao atirar os fardos ao chão, pela distância exigida; sendo muitas vezes atirados de dois a dois, aumentando o peso dos mesmos.

Quanto ao ambiente social de trabalho, estes revelaram algumas características próprias de modelo Taylorista. Havia uma supervisão rígida nos descarregamentos, com o supervisor impondo um ritmo de trabalho, e sempre por perto, que promove um estado de tensão entre os trabalhadores, como observado na fala: "ele tá sempre em cima de nóis..", e complementando quando este se afasta "a gente fica incomodado com isso..". A vigilância era marcada por uma característica autoritária do supervisor, e as relações com o mesmo não eram muito favoráveis para alguns; uma fala de um trabalhador demonstra isso: "ele é um grosso, não dá pra ficar num lugar assim..”, fato também demonstrado em outra fala, de outro trabalhador: “ele pensa que a gente é animal...". O cotidiano de trabalho era marcado por cobranças e constrangimentos nas relações com o supervisor, que transformavam em geral o ambiente de trabalho em um espaço desagradável e tenso.

Em uma fala de um trabalhador notou-se que a tarefa possuía diversas exigências e eram realizadas em ritmo intenso: "aqui a gente tem que fazê de tudo..e tem que fazer sem parar!"; e na fala de outro trabalhador: "a gente tem que correr pra dá conta de fazer tudo, é muita correria...". Um ritmo intenso de trabalho para atingir metas impostas de produção induz o trabalhador a ir além de suas capacidades, além de favorecer a fadiga muscular.

\section{A colocação dos fardos sobre os pallets}

Os fardos eram transportados manualmente de pilhas e colocados sobre os pallets, um a um, ou de dois a dois conforme a largura e o comprimento dos mesmos, aumentando obviamente o peso nos transportes de dois a dois, fato observado quando havia pressa para montar os pallets. A figura 2 abaixo, mostra a colocação dos fardos nos pallets.

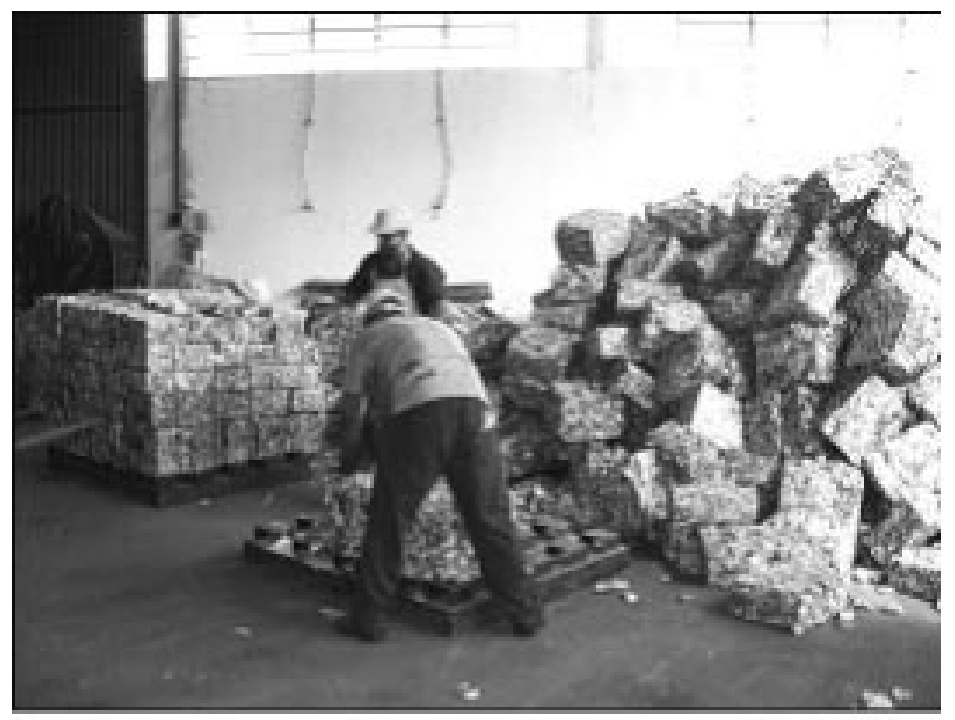

FIGURA 2. Colocação dos fardos nos pallets 
Observaram-se com maior evidência nessa atividade, sob aspectos físicos, os movimentos de flexão e rotação do tronco. Cheng (2000) cita que a inclinação à frente sem apoios adequados de membros superiores proporciona sobrecargas em vértebras lombares, especialmente quando o tronco é fletido além dos $30^{\circ}$. São riscos para lombalgias: movimentos ao erguer uma carga, inclinações laterais e rotações do tronco repetitivas, entre outras. (MARRAS, 2000; GRANATA; MARRAS, 1995).

A tarefa de montar os pallets era realizada também sob pressão temporal, e impossibilitava ao trabalhador pausas no trabalho, como na fala de um trabalhador: "Quando chega o caminhão para carregamento a gente tem que montar todos os pallets rápido, não dá nem tempo para tomar água.. "; sendo que algumas emoções ficavam evidenciadas, como a raiva, observada em fala de outro trabalhador: "às vezes eu tenho vontade de largar tudo, dá raiva...", se referindo ao modo como "a empresa" os trata. Para Smith e Carayon (1996) quando as pessoas estão sob condições emocionais estressoras, o nível de tensão muscular aumenta, independente das exigências biomecânicas; e se estão bravas, este fato pode induzir a métodos impróprios no trabalho, como usar uma força excessiva na execução de determinada tarefa, ou segurar com força uma ferramenta, entre outros. Isso poderia ser explicado, se considerarmos a motricidade não como um movimento qualquer, mas sim como uma das formas de expressão humana.

Bongers et al. (1993) cita algumas associações entre fatores psicossociais e os distúrbios músculo-esqueléticos que são: pressão do tempo que aceleraria os movimentos, e o estresse que eleva a intensidade da contração muscular e aumenta a sensibilidade à dor.

A fala de um trabalhador indica ainda um descontentamento em relação ao trabalho: "isso não é trabalho que preste, só tô aqui porque não achei emprego melhor..."; aspecto também presente na fala de outro trabalhador: "eu não gosto de trabalhar aqui..vou procurar coisa melhor". O descontentamento pode estar relacionado à falta de reconhecimento no trabalho, e as reduções das capacidades dos trabalhadores para ações mecânicas e repetitivas. Em estudo realizado por Ghisleu e Merlo (2005) os trabalhadores apontaram os fatores organizacionais como um dos principais fatores responsáveis pelo desenvolvimento das LER/DORT, sendo para os autores o reconhecimento no trabalho um fator importante.

Algumas propostas foram apresentadas aos trabalhadores, e após concordarem foram encaminhadas à empresa, como: controle quanto aos horários de chegada dos caminhões, e proporcionar pausas nas tarefas de descarregamento e montagem dos pallets. Ainda, que houvesse um número maior de trabalhadores para as tarefas de descarregamento, e rodízios para a execução dessas tarefas entre os trabalhadores (ex: se descarregou um caminhão, não descarrega o próximo); padronização na largura e comprimento dos fardos e evitar que estes estejam com peso superior à $20,0 \mathrm{~kg}$; proporcionar adequações quanto às alturas dos pallets (com controle e regulagem pelas empilhadeiras) para evitar movimentos repetitivos de abaixar-se, experimentar a utilização de tablados de madeira para a retirada dos fardos dos caminhões, elevando a altura dos trabalhadores e evitando movimentos repetitivos de ombros em ângulos de risco para lesões; evitar horas extras de trabalho, e se designadas que sejam previamente informadas e com o consentimento do trabalhador; promover orientações aos trabalhadores quanto aos movimentos de risco; lembrar os trabalhadores quanto ao uso de protetores auriculares, quando a máquina de prensar for ligada.

Ainda, orientar os gestores e supervisor quanto a importância de respeitar os limites das capacidades (físicas) dos trabalhadores, de evitar cobranças excessivas quanto ao tempo de execução, e sobre a importância de se manter um bom ambiente social de trabalho para a saúde do trabalhador. Inserir atividades de terapia corporal, realizadas por terapeutas ocupacionais no final do expediente. Favorecer as relações sociais, com "espaços para o descanso" e eventos. Promover reuniões periódicas com os trabalhadores e junto ao supervisor, com um profissional terapeuta ocupacional que atue na área de saúde e trabalho; para discutir sobre estratégias de melhorias no trabalho. Lancman (2004) cita que para ações de prevenção de adoecimentos ligados ao trabalho é necessário também mobilizar uma transformação social.

Não se pretendeu nesse estudo analisar as demais tarefas dos trabalhadores, porém estas quando realizadas, podem também gerar sobrecargas físicas e mentais, especialmente ao longo do turno de trabalho.

Vários fatores de risco para os distúrbios músculoesqueléticos foram observados e relacionados aos aspectos da organização do trabalho: ritmo intenso de trabalho; pressão temporal, tempo insuficiente de pausas; pobre relacionamento com o supervisor; havendo em geral insatisfação no trabalho, evidenciado também através da alta rotatividade no trabalho entre os operadores de produção.

\section{CONCLUSÕES GERAIS}

Aspectos relacionados à Organização do Trabalho são fundamentais de serem analisados na prevenção dos distúrbios músculo-esqueléticos. A demanda de queixas de dores músculo-esqueléticas foi condizente com a maneira 
que o trabalho era realizado e percepções do trabalho; com fatores de riscos relacionados aos aspectos da organização do trabalho; além dos biomecânicos.

Pesquisas futuras devem investigar e aprofundar as relações entre os distúrbios músculo-esqueléticos e aspectos organizacionais e psicossociais do trabalho, com o intuito de contribuir para a prevenção.

ALENCAR, M do C. B. de. Musculoskeletal disorders and work activities in a recycle company: focusing on the physical aspects. Rev. Ter. Ocup.Univ. São Paulo, v. 20, n. 2, p. 126-134, maio./ ago. 2009.

\begin{abstract}
Musculoskeletal disorders still common at work and still a worry related to health promotion at work. The objective of this study was to investigate risk factors of musculoskeletal disorders in activities of production operator workers of a recycle company. The methods of this study consisted in selection of the tasks perceived as a big physical effort from workers, application of a questionnaire containing: demographic data, questions related to work, questions from the Musculoskeletal Nordic Questionnaire, validated in Brazil (Pinheiro et al, 2002); investigation about the tasks and systematic activities observations, based on Ergonomics (Guérin et al, 1997). Participated in the study six workers, male, and age between 18 and 33 years. The tasks selected for the observations were: empty the trucks ( 3 types) and putting the packs in the pallets. To complement the observations were used the following instruments: video and digital camera (for registering postures), metric band (measures of the packs), chronometer (time/ velocity, pauses/times). In the results were found next to workers musculoskeletal pain in shoulders, elbows, and vertebral spine (lumbar region). Presence of organizational aspects: intense rhythm of work, time pressure, insufficient pause's time, poor relationship with the supervisor; which supports the appearance of musculoskeletal disorders; also found general "insatisfaction" of work. The conclusion is that is important to give attention to organizational and psychosocial aspects of work for prevention.
\end{abstract}

KEY WORDS: Cumulative trauma disorders; Working environment/prevention and control; Work/ psychology; Human engineering; Occupational therapy.

\title{
REFERÊNCIAS
}

ARIENS, G. A. M.; VAN MECHELEN, W.; BONGERS, P. M.; BOUTER, L. M.; VAN DER WAL, G. Psychosocial risk factors for neck pain: a systematic review. Am. J. Industrial Med., v. 39, p.180-193, 2001.

BONGERS, P. M.;WINTER, C. R.; KOMPIER, M. A. J.; ILDEBRANDT, V. H. Psychosocial factors at work and musculoskeletal disease. Scand. J. Work Environ. Health, v. 19, p. 297-312, 1993.

CAMELO, S. H. H.; ANGERAMI, E. L. S. Riscos psicossociais no trabalho que podem levar ao estresse: uma análise da literatura. Ciência, Cuidado e Saúde. Vol.7, n.2, p.232-240, 2008.

CHENG, Y.L. Predicting the vertebral inclination of lumbar spine. Ergonomics, vol.43, p. 744-751, 2000.

COLOMBINI, D; OCCHIPINTI, E. Preventing upper limb work-related musculoskeletal disorders (UL-WRMSDS): new approaches in job (re) design and current trends in standardization. Appl. Ergonomics, v. 37, p. 441-450, 2006.
DAVIES, K. G; HEANEY, C. A. The relationship between psychosocial work characteristics and low back pain: underlying methodological issues. Clin. Biomechanics, v. 15, p. 389-406, 2000 .

DEJOURS, C. A loucura do trabalho. São Paulo: Cortez, 1992.

FALZON, P. Ergonomia. São Paulo: Ed. Blucher, 2007.

FENG, C. K; CHEN, M. L.; MAO, I. F. Prevalence of and risk factors for different measures of low back pain among female nursing aides in Taiwanese nursing homes. BMC Musculoskel. Disorders, 2007. Available from: http://www.biomedcentral. com/1471-2474/8/52. Acesso em: fev. 2008.

FORDE, M. S; PUNNET, L.; WEGMAN, D. H. Pathomechanisms of work-related musculoskeletal disorders: conceptual issues. Ergonomics, v. 45, n. 9, p. 619-630, 2002.

GRANATA, K.; MARRAS, W. EMG-assisted model of biomechanical trunk loading during free-dynamic lifting. $J$. Biomechanics, v. 28, p. 1309-1317, 1995.

GRIECO,A.; MOLTENI, G.; DE VITO, G.; SIAS, N. Epidemiology 
of musculoskeletal disorders due to biomechanical overload. Ergonomics, n. 9, p. 1253-1260, 1998.

GHISLENI, A.P; MERLO, A. R. C. Trabalhador contemporâneo e patologias por hipersolicitação. Psicologia: Reflexão e Crítica, v. 18, n. 2, p. 171-176, 2005.

GUÉRIN, F.; LAVILLE, A.; DANIELLOU, F.; DURAFFOURG, J.; KERGUELEN, A. Compreender o trabalho para transformá-lo: a prática da ergonomia. São Paulo: Ed. Edgard Blucher, 1997.

IIDA, I. Ergonomia: projeto e produção. São Paulo: Edgard Blucher, 2002.

KUMAR, S. Theories of musculoskeletal injury causation. Ergonomics, v. 44, p. 17-47, 2001.

LANCMAN, S. Construção de novas teorias e práticas em Terapia Ocupacional, Saúde e Trabalho. In: LANCMAN, S. (Org). Saúde, Trabalho e Terapia Ocupacional. São Paulo: Roca, 2004.

LANCMAN, S.; UCHIDA, S. Trabalho e subjetividade. Cad. Psicol. Social Trabalho, v. 6, p. 77-88, 2003.

MARRAS, W. S. Occupational low back disorder: causation and control. Ergonomics, v. 43, n. 7, p. 880-902, 2000.

MATOS, E.; PIRES, D. Teorias administrativas e organização do trabalho: de Taylor até os dias atuais, influências no setor saúde e na enfermagem. Texto Contexto Enf., v. 15, p. 508-514, 2006.

MELZER, A. C. S. Aspectos da organização do trabalho e distúrbios osteomusculares: o caso dos trabalhadores das indústrias cerâmicas. Rev. Bras. Promoção Saúde, v. 21, n. 3, p. 161-166, 2008.

MERLO, A. R. C. ; LAPIS, N. L. Saúde e os processos de trabalho no capitalismo: reflexões na interface da psicodinâmica do trabalho e da sociologia do trabalho. Psicol. Sociedade, v. 19, n. 1, 2007.

MINISTÉRIO DA SAÚDE. LER/DORT: protocolos de atenção integrada à saúde do trabalhador de complexidade diferenciada. Brasília-DF, 2006.

PINHEIRO, F. A.; TRÓCCOLI, B. T.; CARVEL, C.V. Validação do questionário nórdico de sintomas osteomusculares como medida de morbidade. Rev. Saúde Pública, v. 36, p. 307-312, 2002.

PUNNET, L.; FINE, L. J.; KEYSERLING, W. M.; HERRIN, G. D.; CHAFFIN, D. B. Shoulder disorders and postural stress in automobile assembly work. Scand. J. Work Environ. Health, v. 26, n. 4, p. 283-291, 2000.

PUNNET, L.; WEGMAN, D. H. Work related musculoskeletal disorders: the epidemiologic evidence and debate. $J$. Eletromyography Kinesiol., v. 14, p. 13-24, 2004.

RIO, R. P. Lesões por esforços repetitivos (LER): uma doença emblemática. Cad. Saúde Pública, v. 13, p. 85-93, 1998.

RUSSO, R. T.; TOLEDO, M. H. C. Corpo sujeito. Movimento Percepção, v. 6, n. 9, p. 6-15, 2006.

SMITH, M. J.; CARAYON, P. Work organization, stress, and cumulative trauma disorders. In: MOON, S. D.; SAUTER, S. L. (Eds.). Beyond biomechanics: psychosocial aspects of musculoskeletal disorders in office work. London: Taylor \& Francis, 1996)

SMITH, D. R.; MIHASHI, M.; ADACHI, Y.; KOGA, H.; ISHITAKE, T. A detailed analysis of musculoskeletal disorder risk factors among Japanese nurses. J. Safety Res., v. 37, p. 195200, 2006. 